\title{
La muerte me da (2007), de Cristina Rivera Garza. Cuerpos desmembrados y de(s)generamiento 0 instrucciones para leer una novela*
}

La muerte me da (2007), by Cristina Rivera Garza. Dismembered bodies and degen(d)eration

or instructions to read a novel

\section{Adlin de Jesús Prieto Rodríguez}

Universidad de Las Américas (UDLA), Quito

DOI: https://doi.org/10.32719/13900102.2018.44.1

Fecha de recepción: 15 enero 2018

Fecha de aceptación: 20 marzo 2018

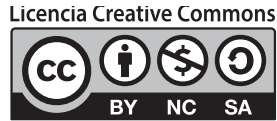

* $\quad$ Este texto forma parte de mi tesis doctoral en proceso titulada "Huellas habitadas: Poética y política del cuerpo en la escritura de Cristina Rivera Garza (o de cómo anclar las múltiples lecturas del cuerpo y sus géneros)". (Universidad Andina Simón Bolívar, Sede Ecuador). Una versión preliminar del mismo fue presentada en el "I Congreso Internacional Acercamientos Interartísticos. Intertextualidad, intermedialidad, transmedialidad 
Una escritura densa basta lo intolerable, hasta la asfixia, pero hecha nada más que de "vinculos sutiles" [...]

Alianzas, metamorfosis.

Alejandra Pizarnik (2002)

la novela, ese (des)género infinito

Cristina Rivera Garza (2004)

\section{RESUMEN}

La muerte me da (2007) de Cristina Rivera Garza es una novela fragmentaria, compuesta por diversos miembros y apartados que aparecen, cercenados, desde el título y siguen esparcidos a lo largo del texto. Estos miembros manifiestan dos tendencias. La primera, la de la fragmentación de la oración, que deviene en fragmentación de la palabra y del cuerpo en/de la novela. La segunda, la estética citacionista y la desapropiación que se traduce en de(s)generamiento. Este artículo se propone mirar por dentro de este cuerpo tajeado para leer el desplazamiento de lo transtextual a lo destextual que remite a la apertura del sentido, la negación, la inversión del significado, la privación, la afirmación y el exceso.

Palabras Clave: Cristina Rivera Garza, La muerte me da (2007), novela contemporánea, transtextualidad, destextualidad, estética citacionista, desapropiación.

\section{ABSTRACT}

La muerte me da (2007), by Cristina Rivera Garza, is a fragmentary novel composed of various members and sections that appear, severed from each other, starting with the title, and that continue to be scattered throughout the text. Such members manifest two tendencies. The first one corresponds to sentence fragmentation, which becomes word fragmentation, as well as fragmentation of the body within/of the novel. The second one corresponds to citationist aesthetics and dis-appropiation, resulting in degen(d)eration. This article intends to look within this slashed body in order to read the the displacement of the trans-textual into the de-textual, wich refers to the opening of meaning, denial, reversal of significance, deprivation, affirmation and excess.

KEYWORDS: Cristina Rivera Garza, La muerte me da (2007), contemporary novel, trans-textuality, de-textuality, citationist aesthetics, dis-appropiation.

en el arte y la literatura en América Latina", organizado por la Universidad Autónoma del Estado de Morelos, en noviembre de 2016. Quiero agradecer al profesor Leonardo Valencia quien en su curso "Temas y autores de la literatura latinoamericana. Arte y teoría de la novela del escritor latinoamericano", dictado en el período julio-agosto de 2015 en la UASB-E, me presentó a Cristina Rivera Garza. En ese momento, surgió en mí el interés por la obra de la mexicana que se mantiene hasta el día de hoy. 
Desde Su APARICIÓn en el marco de la Modernidad, la novela ha sido leída, pensada, problematizada y hasta vilipendiada. Y como producto de la Modernidad, responde a ella: es un género de su tiempo. Por eso, la dificultad de precisarla, de asirla, de clasificarla y su potencialidad de re-invención, re-creación. Los tiempos cambian, la novela también. Y es justo esa metamorfosis de la escritura de la que hablaba Alejandra Pizarnik (2002, 305), esa densidad escritural construida gracias a "vínculos sutiles" la que propongo leer en una novela de los tiempos de hoy, un tiempo "donde la precariedad del trabajo y la muerte horrísona constituyen la materia de todos los días" (Rivera Garza 2013, 19), donde las tecnologías digitales están en auge y expansión. En un tiempo donde la muerte y la pantalla de la computadora, del televisor, del smartphone, de la tablet, están a la orden del día, cuáles son las ficciones que se le presentan al lector, qué le están proponiendo, qué pacto le ofrecen, cómo leerlas. Estas son las preguntas que quiero responder a partir de la lectura de La muerte me da (2007) de Cristina Rivera Garza.

\section{CRISTINA RIVERA GARZA Y SU OBRA}

Cristina Rivera Garza (Matamoros, Tamaulipas, 1964) es una escritora mexicana cuya producción se desplaza entre la Historia y la Literatura. Es Socióloga por la Universidad Nacional Autónoma de México, Doctora en Historia Latinoamericana por la Universidad de Houston, donde actualmente es Profesora Distinguida del Departamento de Estudios Hispánicos y Escritura Creativa (allí dirige el doctorado en español con concentración en Escritura Creativa en Español). Anteriormente formó parte del Departamento de Literatura de la Universidad de San Diego, y de la Escuela Dinámica de Escritores que dirige Mario Bellatin en México. Vive a caballo entre Estados Unidos y México, y desde ese lugar dual, fronterizo, umbroso, de cruces, lee y escribe.

Su producción literaria incluye novelas, cuentos, poesía y ensayos. Una producción que ha sido merecedora de varios premios: 1. "Apuntes”, Premio de Poesía Punto de Partida 1984. 2. La guerra no importa, Premio Nacional de Cuento San Luis Potosí 1987. 3. Nadie me verá llorar, Premio Nacional de Novela José Rubén Romero 1997; Premio Internacional IMPAC-Conarte-ITESM 1999; Premio Sor Juana Inés de la Cruz 2001. 
4. Ningún reloj cuenta esto, Premio Nacional de Cuento Juan Vicente Melo 2001. 5. Premio Internacional Anna Seghers, Berlín 2005. 6. La muerte me da, Premio Sor Juana Inés de la Cruz 2009. 7. Premio Roger Caillois 2013 de Literatura Latinoamericana que otorga el Pen Club de Francia, la Maison de l'Amerique Latine en París y la Sociedad de Lectores y amigos de Roger Caillois.

Aunque explícitamente Rivera Garza ha mencionado que el Crack tiene una historia que no es suya $-\mathrm{y}$ sus integrantes en reiteradas ocasiones han negado su pertenencia al grupo-, se (auto)ubica en el panorama de la literatura mexicana actual en-el-fuera-de-lugar, y ha llegado a la conclusión de que no se pertenece ni a si misma (Hong y Macías 2007). Es innegable la cercanía de sus proyectos literarios con este grupo, así como con el de la Generación de ruptura (Universidad Estatal de San Diego, Literatura de Baja California s. f.) o escritores fronterizos (Williams y Rodríguez 2002).

Más allá de que la autora, al igual que los miembros del Crack, forma parte de la generación de escritores nacidos en el México de los 60, es su obra la que mantiene, de algún modo, "vínculos sutiles" con la de los crackeros. Vínculos que se observan en la construcción de novelas polifónicas en donde se le da cabida a una multiplicidad de voces (En busca de Klingsor de Jorge Volpi sería una muestra de ello, también La muerte me $d a)$, y en la búsqueda estética de un no-tiempo y de un no-lugar. Tanto los miembros de la generación del Crack como Rivera Garza urden en su narrativa historias "cuyo cronotopo, en términos bajtinianos, sea cero: el no lugar y el no tiempo, todos los tiempos y lugares y ninguno" (Manifiesto Crack 2000). A la propuesta novelística de los crackeros-de crear espacios ficcionales que no sean reflejo de la unidad del tiempo-espacio bajtianiana, sino novelas producto "de un fin de siglo trunco de tiempo y lugares, roto por exceso de ligamentos" (Manifiesto Crack 2000)-, Rivera Garza responde a su modo.

La propuesta estética de Rivera Garza también apuesta por el no, el no-lugar, el no-tiempo e incluso la no-identidad; elementos que se presentan en su novela La muerte me da. En cuanto al no-lugar, aunque hay marcas referenciales en ella que permiten ubicar la historia en una ciudad mexicana determinada: Toluca -tanto por la breve alusión a "un lugar a más de dos mil kilómetros sobre el nivel del mar" (Rivera Garza 2007, 59), como por su mención al final de la novela al fecharla-, esa determinación geográfica no es tan relevante para la configuración del relato 
novelesco. En cambio, sí lo es la construcción de una ciudad cosmopolita: dividida por sectores (norte, centro, sur), rodeada de suburbios, con dos o tres clubes Swingers (223). Una ciudad ubicada "dentro de la otra ciudad que la contiene, en su mismo centro, pero también [...] en sus súbitas orillas internas" (125). Una ciudad que posee una oferta cultural importante como la de la instalación de los hermanos Chapman Great Deeds Against the Dead - "Una traducción incompleta, sesgada, real. Un eco de Goya" (25); más bien una muestra de apropiacionismo ${ }^{1}$ de los ochenta y tres grabados de Goya de la serie Los horrores de la guerra, pertenecientes a estos artistas conceptuales ingleses-. El no-tiempo también está presente. La temporalidad es una temporalidad otra, la del "[ $\mathrm{t}]$ odo el tiempo. Tanto tiempo" (37). Una temporalidad que no transcurre en años ni días específicos, sino que tiene una dimensión mensual, sensorial y estacional como la de los "tiempos trémulos y cenicientos de febrero" (37) y la de "la luz de la primavera" (239). De igual modo, la no-identidad tiene cabida: una identidad desplazada donde un nombre ya no designa ni identifica a una persona. Como diría un personaje [el de la periodista de la Nota Roja] de La muerte me da: "Y mi nombre, como te lo imaginas, como lo sabes, como en tu propio caso, mi nombre no soy yo" (92).

De allí que no sea de extrañar que Carlos Fuentes (2011), en La gran novela latinoamericana, la incluya en el grupo de escritores que conforman el Crack, aunque no haya figurado en él originalmente. Además de lo señalado, cabe mencionar que Rivera Garza colabora con los crackeros en diferentes actividades. Una muestra de esto es su participación en el Congreso “Geografías de Carlos Fuentes”, en 2002, junto con Jorge Volpi, Ignacio Padilla y Pedro Ángel Palaou en el que dialogaron sobre la narrativa hispanoamericana en el marco de la conmemoración de los cuarenta años de la publicación de las novelas La muerte de Artemio Cruz

1. El apropiacionismo es un movimiento artístico basado en el procedimiento de la apropiación. Este término se refiere, generalmente, al uso de elementos tomados de una obra determinada para la creación de una nueva. Desde la década de 1980, este vocablo denota el hecho de citar la obra de otro artista para crear otra nueva, pudiendo alterar o no la obra original (Martín Prada 2001).

Es importante destacar que el apropiacionismo es una tendencia conceptualista y que algunos autores, como Rivera Garza por ejemplo, ven en ella el deseo de "regresar al circuito de la autoridad -y del autor-", al volver propio lo ajeno (Rivera Garza 2013, 91). Sobre este punto volveré más adelante. Para más detalles: (Martín Prada 2001; Rivera Garza 2013). 
(1962) y Aura (1962). Otra muestra es el libro de ensayos Palabra de América (2004) que recoge las ponencias presentadas por los asistentes al Primer Encuentro de Escritores Latinoamericanos, que Seix Barral promovió en Sevilla a finales de junio de 2003, y que fue a la vez un homenaje al desaparecido Roberto Bolaño. Participaron en el encuentro varios autores, entre ellos: Ignacio Padilla, Cristina Rivera Garza y Jorge Volpi (Bolaño et al 2004). Otro de los grupos al que ha sido asociada Rivera Garza es al que la crítica bajacaliforniana ha denominado Generación de ruptura (Universidad Estatal de San Diego, Literatura de Baja California s. f.) o escritores fronterizos (Williams y Rodríguez 2002). Grupo surgido entre 1980 y 1990, y compuesto, mayoritariamente, por escritores radicados en los estados fronterizos mexicanos. Está integrado por escritores como Luis Humberto Crosthwaite, Daniel Sada y Marco Antonio Samaniego, entre otros. Según el grupo de estudios de Literatura Bajacaliforniana de la Universidad Estatal de San Diego (s. f.), el rasgo principal de los rupturales (o fronterizos) es el manejo lingüístico de la expresión lírica y la relación lúdica que establecen los escritores con las convenciones literarias, a las que no se supeditan. Los une también el panorama geográfico: la frontera desde la cual y sobre la cual escriben. Este movimiento ruptural se caracteriza además porque sus integrantes abordan los problemas de la frontera a partir del empleo de ciertas técnicas narrativas como la hibridación de géneros y recursos como la parodia, lo grotesco y lo fantástico. Así como por el cuestionamiento del status quo, la falta de movilidad política y social, la construcción de personajes escindidos y ambiguos. Es una producción heteroglósica y fragmentaria que da voz a múltiples discursos. En el caso de Rivera Garza, la crítica literaria bajacaliforniana considera que su obra presenta estos rasgos (Universidad Estatal de San Diego, Literatura de Baja California s. f.).

\section{LA MUERTE ME DA (2007)}

La muerte me da es una novela que consta de ocho capítulos y noventa y cuatro apartados. Comienza con la voz de la informante que da cuenta de la aparición/descubrimiento de un hombre joven, muerto y castrado mientras corría por las calles de la ciudad donde transcurre la historia. Esta voz en primera persona de la informante no es una mono- 
lógica. Al contrario, hay en esta novela una pluralidad de voces: la de la detective, la de la periodista de la Nota Roja y la de Valerio -el ayudante de la detective, la única voz masculina y el único personaje masculino no incidental en el relato-, quienes desde la primera persona presentan el caso de los homicidios seriales de los hombres castrados. A ellas, se les suma la omnisciente que también está en la novela. Estas voces posibilitan, por un lado, el adentramiento en el punto de vista de cada uno de los actores acerca de los asesinatos y, por el otro, la sensación de lejanía y cercanía de los hechos (dada por la introducción al lector al discurso de los personajes y por la conversación que, en ocasiones, entablan entre ellos).

Esta novela se inscribe en una doble tradición: la de la literatura de la violencia, tendencia asociada de algún modo a la narrativa de la frontera, y la de la narrativa policíaca. Ha sido leída como una novela del género negro que trasciende las reglas del mismo, al punto de ser considerada más bien como una antidetective fiction (Spanos 1972) o policial metafísico, ${ }^{2}$ categoría que engloba una variedad de textos en los que la investigación no llega a buen fin y frustra la necesidad del orden (reestablecido) del sujeto moderno. Aunque fue Spanos (1972) quien en su ensayo "The Detective and the Boundary. Some Notes on the Postmodern Literary Imagination" introdujo el concepto de antidetective fiction y su vinculación con el policial metafísico, ha sido Stefano Tani quien ha continuado la reflexión sobre el mismo y presentado el análisis más completo hasta el momento. Tani (1984) identifica tres variantes de la novela policial antidetectivesca: la innovadora, que se fija en la parodización del modelo policial clásico; la variante deconstructiva que pone su acento sobre el caos y la aciaga realidad; y la variante metaficcional donde la investigación detectivesca no es sino una metáfora de la reflexión sobre el proceso mismo de escritura y de interpretación del texto (40). Este último es el caso de La muerte me da, como bien menciona Francisca Noguerol (2009). ${ }^{3}$

2. Tendencia narrativa que surge a partir de los años noventa y cuyo precursor en América Latina sería el Borges de "Abenjacán el Bocarí muerto en su laberinto": "la solución del misterio siempre es inferior al misterio" (Borges 1975, 605).

3. Noguerol (2009) apenas menciona la novela de Rivera Garza como un ejemplo de esta tercera vertiente, no desarrolla esta idea. Su aporte consiste en presentar la fórmula narrativa del relato policial mexicano, especialmente desde 1968 hasta la actualidad. Para ello, establece dos tendencias principales: la del neopolicial -que ha sido canonizado por Paco Ignacio Taibo II y que fue dominante desde los setenta hasta los noventa- y la ficción antidetectivesca o policial metafísico -predominante desde los años noventa-. 
Siguiendo esta línea metaficcional propuesta por Tani (1984), veo en La muerte me da cómo Rivera Garza realiza un ejercicio de escritura que es esencialmente un acto de lectura textualizado y convertido en relato novelesco. Un acto de lectura que trasciende el espacio textual físico del formato libro y que se le plantea al lector desde el título mismo de la novela: "La muerte me da", un fragmento extraído de los Diarios de Alejandra Pizarnik (2014) del jueves 24 de enero de 1963 y que originalmente es: "Es verdad, la muerte me da en pleno sexo" (315). Ya de entrada, desde el título de la novela se presentan dos tendencias que se mantendrán a lo largo de la misma. La primera, la de la fragmentación de la oración, de la frase, que deviene en fragmentación de la palabra y del cuerpo en/de la novela. La segunda, la estética citacionista y la desapropiación que se traducirá en de(s)generamiento.

\section{EL CUERPO DESMEMBRADO EN/DE LA NOVELA}

Si tomamos en cuenta los peritextos que abren y cierran la narración; a saber, la pregunta de la teórica y feminista francesa Hélène Cixous que inicia la novela - "víctimas de las preguntas: ¿quién me está matando?, ¡a quién me estoy entregando para que me mate?” (Rivera Garza 2007, 11) - y la cita del poeta egipcio-francés y judío Edmond Jabès que la concluye -"Violamos un libro para leerlo, pero lo ofrecemos cerrado" (354)-, podemos considerar que el lector se encuentra ante un intervalo: el de una violencia que se inscribe en el cuerpo y en el acto de leer. Este intervalo ofrece un marco de lectura determinado, como diría Genette (2001), un umbral desde el cual aproximarse al texto. Una aproximación signada por la castración (de los hombres asesinados) y la violación del texto, que pasa por el cercenamiento de órganos vitales del cuerpo humano y por la profanación de un texto -no solo para leerlo, sino también para escribirlo, producirlo- o, lo que es lo mismo, que pasa por la analogía del cuerpo y cuerpo de la novela. Aunque es mucho más evidente y notoria la mutilación de los genitales de los hombres asesinados, de los cuerpos castrados con cuya aparición inicia la novela gracias a la declaración farfullada de la informante, también es cierto que hay una mutilación otra: la del lenguaje. Una mutilación más relevante que pone en escena la materialidad de 
la lengua y su potencialidad para representar el sentido que interrumpe la significación, que la corta.

La aparición de los hombres castrados, de esos asesinatos seriales, la puesta en escena de los mismos cual instalación artística, la escenificación de un "cuerpo sobre la calle, un cuerpo tan cercano de otro verso de Pizarnik, $[\ldots]$ delineado con lápiz de labios sobre el pavimento" (Rivera Garza 2007, 225), da cuenta de "un esteta [...] que quiere darnos un mensaje sobre el cuerpo, el cuerpo masculino, y las letras del alfabeto" (226). Por ello, no solo es crucial que sean los versos brutales de la poeta argentina Alejandra Pizarnik que dicen cosas brutales (24) los seleccionados por el/ la asesin@ para dejarlos como indicios en la puesta en escena del crimen, sino también la presencia de la construcción de una nueva gramática de la que hablaba Pizarnik, la que había que aprender, para dar cuenta de ello. Una nueva gramática para contar/escribir la muerte, sobre la muerte. "Escribir: muerte. Separar las sílabas. Desentrañar letras. Escribir la muerte. Abrirla" (313; énfasis en el original). Una nueva gramática y sintaxis hecha de fracturas, de miembros. Unos miembros que dejaron de ser corpóreamente humanos para convertirse esencialmente en vocablos. Una nueva lengua que habla, que dice, que cuenta otro tipo de muerte y otro tipo de crimen: el de la escritura y el de la lectura. Una lengua en la que el cuerpo del texto dice y abre una herida: la del sentido para decir, "¿¿ $[\mathrm{n}] \mathrm{O}$ tenía [...] esa malsana curiosidad de "mirar por dentro"? ¿Sería suficiente esa curiosidad como para abrir la herida? ¡Y no era eso, a fin de cuentas, escribir?" (242).

Esta escritura de/sobre la muerte -que al fin y al cabo es toda escritura -4 es una necroescritura que incorpora "prácticas gramaticales y sintácticas, así como estrategias narrativas [...], que ponen en cuestión el estado de las cosas y el estado de nuestros lenguajes" (Rivera Garza 2013, 33). Una escritura cuya práctica hace que la lengua natal castre (Pizarnik en Rivera Garza 2007, 55), que el cuerpo humano equivalga al texto en cuanto

4. En este sentido, sigo la línea argumental de Deleuze de que la escritura es siempre una necroescritura, se escribe para la muerte: "La literatura empieza con la muerte del puerco espín, según Lawrence, o la muerte del topo, según Kafka: 'nuestras pobres patitas rojas extendidas en un gesto de tierna compasión'. Se escribe para los terneros que mueren, decía Moritz" (Deleuze 1996, 6). Esta noción de necroescritura es compartida por Rivera Garza (2013), su reflexión sobre este punto es desarrollada en Los muertos indóciles. Necroescrituras y desapropiación. 
ambos son superficies en la que se inscribe un deseo, un suceso, un yo, un cadáver, una historia. “Todo es superficie” (Rivera Garza 2007, 87), y para leer el sentido que hay en ella "[e]l que analiza, asesina [...]. El que lee con cuidado, descuartiza.” (88). Hace grietas, corta. Leer es, en este sentido, seguir el llamamiento de la superficie que puede/quiere recibir el tajo. Escribir, también. Es justo este tajo el mensaje sobre el cuerpo y las letras que quiere darnos el texto/cuerpo. El tajar posibilita la configuración de una nueva lengua o, como dice Proust (1954), trazar, a través y gracias a la literatura a la estética, una especie de lengua extranjera, que no es otra lengua sino un devenir otro de la lengua, una línea que escapa del sistema dominante, que lo corta y en ese corte, en ese fragmento (re)(des)significa. La estética del tajo es la propuesta que se presenta en La muerte me da.

\section{DE LA TRANSTEXTUALIDAD}

\section{A LA DESTEXTUALIDAD}

"Escribir, desde esta perspectiva, equivale a inscribir algún signo sobre la superficie de un cuerpo desmembrado o bien, simplemente, a dejar que la lengua misma se descuartice" (Rivera Garza 2007, 178). Estas palabras de la escritora, poeta, ensayista, novelista y traductora argentina María Negroni abren el apartado -yo prefiero pensar/decir el tajo- "El anhelo de la prosa" de La muerte me da (176). Desmembrar, tajar, descuartizar son vocablos que remiten a la separación, a la división de un cuerpo. Este peritexto, como todos los que aparecen en La muerte me da, es uno de los tantos miembros, fragmentos, apartados que componen el cuerpo de la novela, del texto. Miembros cercenados que aparecen desde el título de la misma, y que siguen esparcidos a lo largo de la superficie del relato. Miembros que son en realidad la manifestación de una estrategia narrativa: la transtextualidad (Genette 1989).

La transtextualidad, o "trascendencia textual del texto", es un concepto propuesto por Gérard Genette (1989) para denominar los diferentes modos que "pone[n] al texto en relación, manifiesta o secreta con otros textos” (9-10). Según este teórico y narratólogo, hay cinco modos de hacerlo: la architextualidad, la hipertextualidad, la intertextualidad, la metatextualidad y la paratextualidad. De estos cinco tipos de relaciones transtextuales, La muerte me da presenta cuatro que convergen en lo que 
se ha denominado estética citacionista y práctica de la desapropiación. La primera que se presenta, y probablemente la más "evidente", es la intertextualidad que se observa desde el título de la novela. Como se ha mencionado antes, el título es producto de la desmembración de una oración extraída de los Diarios de Alejandra Pizarnik. Una desmembración, extracción y referencialidad iniciada en el nombre de la novela, que se mantiene a lo largo de la misma hasta el final cuando en el penúltimo apartado se alude a la muerte de esta escritora al mencionar la fecha: "Hoy no es el 25 de septiembre de 1972" (Rivera Garza 2007, 352). Una desmembración que (re)aparece gracias a la presencia de un poema de la poeta argentina al lado de cada uno de los cadáveres en la puesta en escena de cada crimen. Gracias también a la intercalación de versos (en ocasiones en cursivas, en otras no) durante el transcurso de la historia como otra forma de contarla. La "evidencia" de esta intertextualidad no siempre es tan clara. En algunos casos, como el del título y la intercalación de versos sin destacarlos de algún modo gráfico, la referencia intertextual es implícita (no se menciona en ningún lugar a la autora de esas frases y versos). En otros, la alusión es directa. Es el caso, por ejemplo, del poema "En esta noche, en este mundo" que muestra la Detective asignada al caso de los hombres castrados al interrogar a la informante, Cristina, y a la que le "informaba en ese momento, Pizarnik publicó en la Gaceta del Fondo de Cultura en julio de $1972 "(54-55) .^{5}$

La segunda evidencia es la paratextualidad, especialmente la peritextual. En La muerte me da hay una abundancia de peritextos. No solo los correspondientes al criterio editorial como la imagen de la portada, el texto de la contraportada y la información sobre la autora en la solapa del libro; sino también, y especialmente, los que están en el interior del cuerpo de la novela: los epígrafes que abren cada capítulo y que enmarcan, de algún modo, su lectura e incluso la de la novela como se explicó en el apartado anterior. De todos los peritextos presentes, sobresale inusitadamente

5. Hay una relación intertextual implícita con Los viajes de Gulliver (1726) al nombrar un capítulo de La muerte me da (2007) como Grildrig -nombre con que los gigantes de Brobdignag identifican a Gulliver- que se convierte en una explícita al incorporar en él un epígrafe de Los viajes de Gulliver (1726) en su idioma original y al construir un personaje femenino, la Mujer Increíblemente Pequeña, con ese nombre.

Para un estudio detallado de esta intertextualidad y de sus implicaciones paródicas, subversivas y fantásticas: (Alicino, 2014, 181-91). 
el prólogo del poemario homónimo de la novela, un poemario que se incrusta en ella y (con)forma otro miembro de este cuerpo desmembrado.

La forma en que opera este poemario, el epígrafe y el prólogo del mismo es una que abre líneas de fuga hacia adentro y fuera del texto. Este miembro/poemario por un lado, hacia el interior del cuerpo-texto, establece relaciones intratextuales entre dos de los personajes de la novela: la informante y la periodista de la Nota Roja y el miembro/poemario. En la reunión que sostuvieron a propósito de la visita de la periodista a la informante, cuyo nombre es Cristina Rivera Garza -escritora, profesora universitaria y editora-, con el objeto de conversar sobre el tema del libro que aquella quería escribir para sí y no para el periódico, Cristina reflexiona sobre escribir un libro para sí:

Un libro -para mí, hecho por mí-, el viaje de la conciencia por un estado. Pensé en ese pedazo de texto. Pensé en esas palabras de Caridad Atencio. Pensé en la arrogancia o el candor que se necesita para decir: escribo un libro para mí. Pensé en la disciplina, en el aislamiento, en la necedad que se requiere para llegar a hacerlo. Escribir un libro para mí, hecho por mí. Te lo dije así cuando apareciste tras la puerta: un libro para mí, hecho por ti. Y lo repetí varias veces frente a tu sonrisa. Y luego la observé otra vez (51; énfasis en el original).

Este pensamiento de Cristina que parece ser compartido con un tú que no sabemos exactamente quién es y que hace referencia a una tercera persona, la periodista de la Nota Roja, termina con una interrogante que interpela a esta: “-¿Y quieres entrevistarme?” (51), sobre el caso de los hombres castrados. Una interrogante que sorpresivamente es respondida con un rotundo no, seguido por un deseo: "Quiero platicar con usted sobre Alejandra Pizarnik" (52).

El personaje de la periodista de la Nota Roja-que funciona en el relato como uno sospechoso de "manos ajadas por labores sin identificar pero claramente no intelectuales [...]" (50), y que "explica" "con algo de evidente vergüenza, que ella era en realidad una periodista" (50)- no llega a sostener esa plática con Cristina, aunque sí inicia una correspondencia unilateral con ella en la que le envía doce mensajes signados por la sospecha que es al fin y al cabo lo que deja: la sospecha de la/su identidad, al firmar cada mensaje con un nombre distinto; la sospecha de la escritura, al intervenirla con frases y versos de Pizarnik y al emularla; y la de su 
culpabilidad en el caso de los crímenes de los hombres castrados, pues hay indicios, aunque insuficientes, de que ella es la asesina. Pero la certeza de su culpabilidad, “[e]so no lo puede saber la novela” (107).

Esta sospecha se desplaza al poemario/miembro e interpela al lector cuando lee como epígrafe justo las palabras de Caridad Atencio, que pensara Cristina al conversar con la periodista. Un pensamiento que no se llegó a articular, a vocalizar. La sospecha sigue in crescendo cuando el editor Santiago Matías de la Editorial Bonobos, de la ciudad de Toluca (México), da cuenta en el prólogo del poemario La muerte me da de las circunstancias en las cuales recibió el texto y la solicitud de que fuera considerado para ser publicado en la serie de poesía del sello editorial que dirige. Circunstancias llenas de enigmas que se cristalizan en el nombre de su autora: Anne-Marie Bianco. Un nombre al que Matías le construye una genealogía literaria, poética y ficticia al desear darle sentido a la enigmática autora. Una genealogía fundada en un ancestro literario inexistente, ${ }^{6}$ y que fue el seudónimo empleado por un grupo de poetas, según Matías, que publicaron en los sesenta y setenta. Poemas cuya estética podía ser definida con dos palabras: rota e inquietante (Matías citado por Rivera Garza 2007, 304).

Un seudónimo que remite a "una irreconciliable contradicción: Bruno (oscuro) Bianco (blanco). Bruno Bianco: extraño personaje que quizá jamás existió (al menos físicamente)” (304), y que solo vive en los cómics italianos del cual es protagonista (Accorsi 2012). Un seudónimo que evidencia el gesto de darle un cuerpo al fantasma de la autora: Anne-Marie Bianco, "una autora sin rostro" (306). Un rostro que es solo texto, uno por el que la pequeña editorial Bonobos puede darse el lujo de apostar "por un puro texto, por el texto" (306). Un texto que ronda obsesivamente dentro de la poesía pizarnikiana.

El prólogo de Matías finaliza planteando un acertijo a los lectores: el de construir con la lectura el rostro de la autora e involucrarse en el enigma de su escritura. $\mathrm{Al}$ aceptar responder el acertijo, se alcanza el clímax de la sospecha del miembro/poemario. El otro lado, la otra dirección

6. Bruno Bianco fue, en efecto, el seudónimo con el que aparecieron firmados un par de poemas en la década de los noventa, mismos que se incluyen, a modo de genealogía ficcional, después de los poemas firmados por Anne-Marie Bianco. Este seudónimo imposible, se ha dicho, reunió la autoría de, al menos, Guillermo Fernández, Francisco Hernández, Vicente Quirarte, entre otros. 
de la línea de fuga, la del afuera del texto. Si bien es cierto que el poemario La muerte me da aparece incrustado en la novela homónima que fue editada por Tusquets en 2007, también lo es que fue publicado como texto independiente por la Editorial Bonobos en ese año. Es decir, el poemario no solo es un miembro, un tajo de La muerte me da (novela), sino que tiene una entidad libresca propia. Es un texto que existe como publicación autónoma y que también existe en el espacio ficcional de la novela. Si a eso le sumamos otros elementos, la línea de fuga se intensifica y se desparrama fuera del texto. El primero sería la aparición de ambos textos, poemario y novela, el mismo año. El segundo, el carácter autoficcional de esta dado por la construcción de un personaje femenino, la informante Cristina Rivera Garza, cuya identidad nominal y oficios son iguales a los de la autora y que además es la narradora, más bien uno de los narradores, y protagonista del relato novelesco (Lecarme 1994). ${ }^{7}$ El último, el hecho de que en la obra poética de la escritora mexicana Cristina Rivera Garza aparece el poemario La muerte me da (aunque firmado con el seudónimo de Anne-Marie Bianco, co-editado por dos instituciones a las que está ligada institucionalmente la Editorial Bonobos y el Instituto Tecnológico y de Estudios Superiores de Monterrey [ITESM] -mejor conocido como Tecnológico de Monterrey). Hay pues una relación extratextual e intertextual que problematiza la lectura del cuerpo/novela y, especialmente, la figura del autor.

Este avecinamiento de los textos imposibilita deslindar cuál de los dos La muerte me da, el poemario o la novela, es el texto B (hipertexto) y cuál es el texto A (hipotexto) que sería previo al $\mathrm{B}$ y un antecedente del que se originaría este. Este avecinamiento permite pensar la presencia de una hipertextualidad otra, una hipertextualidad indeterminada en $L a$ muerte me da. En este caso, no importa cuál texto incluye al otro. Lo relevante, lo transgresor, es esa alteración de la relación hipertextual; es decir, la hipertextualidad se da en un sentido otro, uno no unívoco, sino bidireccional.

Antes de abordar con más detalle el problema de la autoría -a partir de lo explicado-, quiero presentar la última relación transtextual que

7. 'L'autofiction est d' abord un dispositif tres simple: soit un recit dont auteur, narrateur et protagonista partagent la meme identite nominale et dont l'intitule generique indique qu'il s'agit d'un roman" (Lecarme 1994, 227). 
observo en la novela La muerte me da: la metatextualidad. Generalmente, la metatextualidad es entendida como una relación textual de comentario; es decir, es una relación crítica que establece un texto sobre otro al referirse a él. También se entiende por metatextualidad la mirada crítica, (auto)reflexiva, que un texto construye sobre sí mismo. En La muerte me da estos dos modos de metatextualidad conviven y respiran en el mismo cuerpo, el de la novela. El primero, el del comentario, se observa claramente en el tajo con cuyo epígrafe inicié este apartado: "El anhelo de la prosa". Este capítulo que además está identificado con el nombre de la Dra. Cristina Rivera Garza, que da cuenta de su adscripción institucional al ITESM-Campus Toluca, y advierte la prohibición de este texto por estar siendo sometido a dictamen de publicación en la revista Hispamérica-una de las publicaciones de referencia del latinoamericanismo internacional, editada desde 1972 por la Universidad de Maryland y dirigida por el intelectual argentino Saúl Sosnowksi- es un ensayo sobre el muro de la poesía de Alejandra Pizarnik. Un muro que la poeta deseaba romper en su deseo de escribir prosa. Partiendo de los diarios y de la narrativa completa de Pizarnik, Rivera Garza (2007) se propone en este ensayo “dilucidar [... los hilos que se enredan en el anhelo pizarnikiano de la prosa" (181), leer a la Pizarnik que se dedicó a pensar las limitaciones de la poesía y a buscar "una prosa [...] un lenguaje concreto que le permita un día escribir una novela" (Becciu citada por Rivera Garza 2007, 181; énfasis en el original).

El segundo modo, el de la (auto)referencialidad crítica, se da de forma dual. La primera remite a esa variante metaficcional de la novela policial antidetectivesca (Tani 1984), donde la investigación que no se resuelve y el caso que se presenta no son más que un pre-texto para textualizar una concepción determinada de la escritura y de la interpretación del texto. No importa quién es el culpable, el autor del crimen, de la escritura, solo importa lo producido: el cuerpo muerto, el cadáver, el texto, y lo que significa y/o puede llegar a significar, la interpretación. La segunda, en la pene-tración, al pen-entrar el cuerpo de la novela con el ensayo "El anhelo de la prosa". En este acto de pene-tr-a(c)ción Rivera Garza intenta resolver un enigma otro, ya no el de los hombres castrados, sino el de los cercos de los géneros. Si la "prosa pizarkiana corta con frecuencia los hilos del significado del lenguaje a través de líneas o párrafos que toman la forma de fragmentos." (Rivera Garza 2007, 184), la prosa riveragarceana castrará cuerpos masculinos, vocablos, parte del relato. Ante la escritora 
argentina que "reflexiona, línea tras línea, palabra tras palabra sobre su oficio" (185), la escritora mexicana escribirá una novela que línea tras línea, corte tras corte, tajo tras tajo ficcionalizará una reflexión sobre su oficio. Al “'Problema de los límites de la poesía, de los cercos. O el poema en prosa”" (Pizarnik citada por Rivera Garza 2007, 185), que también necesita cercos, planteado por Pizarnik, Rivera Garza responderá desde “un hacer material que no solo atañe al entre sino también al intra que junta pero no funde géneros literarios de carácter propio" (Rivera Garza 2007, 185; el énfasis es mío).

De allí que puedan leerse en La muerte me da las múltiples maneras en que ese anbelo de la prosa pizarnikiana se cumple de algún modo. Lo que plantea Rivera Garza en "El anhelo de la prosa” es lo que hace en términos escriturales en La muerte me da. En estas relaciones transtextuales, en ese trans- que remite "al otro lado", al "a través de", podemos leer también un des-doblamiento: el de la autoría y escritura. Una relación que se problematiza a partir de la estética citacionista dada por la intertextualidad con la obra de Pizarnik, especialmente, y por la materialidad de un sujeto (ficcional) que construye un objeto cultural: Anne-Marie Bianco como autora del poemario La muerte me da, que también establece una relación intertextual con la obra pizarnikiana. Un des-plazamiento del trans- al des- en cuyo devenir a un des-algo remite a la apertura del sentido, al de la negación, la inversión del significado, la privación, la afirmación, el exceso y al "fuera de".

\section{DE LA ESTÉTICA CITACIONISTA, LA DESAPROPIACIÓN Y EL DE(S)GENERAMIENTO (O INSTRUCCIONES PARA LEER UNA NOVELA)}

Estas transtextualidades podrían ser pensadas como destextualidades. Como una modalidad narrativa hacia la apertura del signo y del significante. Una textualidad otra en diálogo con la concepción riverogarceana del texto citacionista: el "compuesto por la relación social, dinámica, contestataria, colectiva que un autor establece con un lenguaje en uso constante. Un texto citacionista es [...] un texto "con-ficcionado" (Rivera Garza 2013, 81). Es decir, un texto cosido, hecho de retazos, de fragmentos, de miembros colectivos cuya materia prima es el lenguaje de 
(nos)otros. Un texto creado en/desde la cercanía del lenguaje de otros des-apropiando más que apropiando el bien común del lenguaje. En este sentido, la escritura sería una práctica de desapropiación, realizada en comunidad, relacionalmente, gracias a un hacer material que atañe al entre $y$ al intra, en tanto se vive una experiencia de pertenencia con el lenguaje y el trabajo colectivo de/con otros constitutiva del texto (23). Una práctica opuesta por completo a la apropiación, en la que la figura del autor único, interno, poseedor del significado se remarca; en la que se retorna al circuito de la autoridad y del autor siempre aunque varíen los medios.

Si nos remitimos a la definición del vocablo desapropiar, (de des- y apropiar) a la de desposeerse del dominio sobre lo propio, es más sencillo seguir la propuesta de la desapropiación como una práctica escrituraria del estar-en-común, de entender a la escritura como un devenir, un asunto inacabado, en curso. De allí que podamos pensar también a la escritura como un ejercicio de de(s)generamiento mediante el cual se materializa la tensión constante e irresoluble que se produce en la colindancia de lo distinto (Rivera Garza 2007 [2006], 80). La idea no es borrar los géneros; al contrario, es reconocer su existencia a través de la confrontación dialógica. Por eso la novela es el de(s)género por excelencia: posibilita la colindancia de todos los géneros, abre líneas de fuga en su cuerpo y ante los límites fronterizos cerrados, abre trochas, tajos de palabras y sentidos. Y ante ese estar-en-común del escribir hay un estar-en-común otro, el del leer. El leer sería un compartir la pertenencia de la interpretación colectiva.

Por todo lo anterior, La muerte me da es una metanovela. Es un cuerpo cuya (auto)inscripción da cuenta del diálogo que establece con un modo de escribir que excede el cerco de los géneros, con una comunidad de escritura deseante, anhelante, reflexiva y que construye dentro de sí a un lector que al leer (re)con-ficciona el cuerpo al urdir los retajos que lo componen. Un lector que también forma parte de ese (nos)otros del lenguaje deseante, del lenguaje múltiple, del lenguaje errante. * 
KİPUS 44, julio-diciembre 2018

\section{Bibliografía}

Accorsi, Andrés. 2012. "El Negro Blanco Vol.7”. En 365 comics por año. 10 de julio. Disponible en http://365comicsxyear.blogspot.com/2012/07/10-07el-negro-blanco-vol7.html .

Alicino, Laura. 2014. "Lo 'fantástico intertextual'. En La Muerte me da de Cristina Rivera Garza”. En Sobrenatural, fantástico y metarreal: La perspectiva de América Latina, editado por Bárbara Greco y Laura Pache Carballo, 181191. Madrid: Siglo XXI.

Bianco, Anne-Marie. 2007. La muerte me da. Toluca: ITESM-Bonobos.

Borges, Jorge Luis. 1975. Obras completas. Buenos Aires: Emecé Editores.

Deleuze, Gilles. 1996 [1993]. Crítica y clínica. Barcelona: Anagrama.

Fuentes, Carlos. 2011. La gran novela latinoamericana. México: Alfaguara.

Genette, Gérard. 1989. Palimpsestos: la literatura en segundo grado. Madrid: Taurus.

—. 2001. Umbrales. México: Siglo XXI.

Hong, Jung-Euy, y Claudia Macías Rodríguez. 2007. "Desde México para Corea. Entrevista a Cristina Rivera Garza". Espéculo. Revista de estudios literarios. Universidad Complutense de Madrid. Disponible en 〈http://www.ucm.es/ info/especulo/numero35/crisrive.html.

Lecarme, Jacques. 1994. “Autofiction: un mauvais genre?”. Autofictions \& Cie. n. ${ }^{\circ}$ 6: 227-249.

“Manifiesto Crack”. 2000. Lateral. Revista de Cultura, n. ${ }^{\circ}$ 70. Disponible en 〈https://es.scribd.com/doc/64919561/Manifiesto-Crack〉.

Martín Prada, Juan. 2001. La apropiación posmoderna: arte, práctica apropiacionista y teoría de la posmodernidad. Madrid: Fundamentos.

Noguerol Jiménez, Francisca. 2009. “Entre la sangre y el simulacro: últimas tendencias de la narrativa policial mexicana". En Tendencias de la narrativa mexicana actual, editado por José Carlos González Boixo, 169-200. Madrid: Iberoamericana-Vervuert.

Pizarnik, Alejandra. 2002. "Apuntes para un reportaje”. En Prosa completa. Barcelona: Lumen.

—. 2014. Diarios. Edición a cargo de Ana Becciu. Barcelona: Lumen.

Proust, Marcel. 1954. Contre Sainte-Beuve. París: Gallimard.

Rivera Garza, Cristina. 2004. "Blogsívela. Escribir a inicios del siglo XXI desde la blogósfera”. En Palabra de América, editado por Roberto Bolaño et al., 167 179. Barcelona: Seix Barral.

- 2007 [2006]. "La escritura solamente". En El arte de enseñar a escribir, 2. ${ }^{\text {a }}$ ed., coordinado por Mario Bellatin, 78-82. México: Fondo de Cultura Económica / Escuela Dinámica de Escritores.

- 2007. La muerte me da. México: Tusquets.

—. 2013. Los muertos indóciles. Necroescrituras y desapropiación. México: Tusquets. 
Spanos, William. 1972. "The Detective and the Boundary: Some Notes on the Postmodern Literary Imagination". Boundary, 2. 1: 147-168.

Tani, Stefano. 1984. The Doomed Detective: The Contribution of the Detective Novel to Postmodern American and Italian Fiction. Texas: Sothern Illinois University Press.

Universidad Estatal de San Diego, Literatura de Baja California. s. f. La novela. Disponible en 〈https://larc.sdsu.edu/baja/genero/novela.html .

Williams, Raymond, y Blanca Rodríguez. 2002. La narrativa posmoderna en México. México: Universidad Veracruzana. 